\title{
MicroRNAs in Hearing Disorders: Their Regulation by Oxidative Stress, Inflammation and Antioxidants
}

OPEN ACCESS

Edited by:

Jian Zuo,

St. Jude Children's Research Hospital, United States

Reviewed by: Kimberly Raab-Graham, Wake Forest School of Medicine, United States Kelvin Y. Kwan,

Rutgers University, The State University of New Jersey, United States

*Correspondence: Kedar N. Prasad knprasad@comcast.net

Received: 02 June 2017 Accepted: 28 August 2017 Published: 11 September 2017

Citation: Prasad KN and Bondy SC (2017) MicroRNAs in Hearing Disorders: Their Regulation by Oxidative Stress, Inflammation and Antioxidants.

Front. Cell. Neurosci. 11:276. doi: 10.3389/fncel.2017.00276

\author{
Kedar N. Prasad ${ }^{1 *}$ and Stephen C. Bondy ${ }^{2}$ \\ ${ }^{1}$ Engage Global, San Rafael, CA, United States, ${ }^{2}$ Center for Occupational and Environmental Health, Department \\ of Medicine, University of California, Irvine, Irvine, CA, United States
}

MicroRNAs (miRs) are small non-coding single-stranded RNAs that bind to their complimentary sequences in the $3^{\prime}$-untranslated regions (3'-UTRs) of the target mRNAs that prevent their translation into the corresponding proteins. Since miRs are strongly expressed in cells of inner ear and play a role in regulating their differentiation, survival and function, alterations in their expression may be involved in the pathogenesis of hearing disorders. Although increased oxidative stress and inflammation are involved in initiation and progression of hearing disorders, it is unknown whether the mechanisms of damage produced by these biochemical events on inner ear cells are mediated by altering the expression of miRs. In neurons and non-neuronal cells, reactive oxygen species (ROS) and pro-inflammatory cytokines mediate their damaging effects by altering the expression of miRs. Preliminary data indicate that a similar mechanism of damage on hair cells produced by oxidative stress may exist in this disease. Antioxidants protect against hearing disorders induced by ototoxic agents or adverse health conditions; however, it is unknown whether the protective effects of antioxidants in hearing disorders are mediated by changing the expression of miRs. Antioxidants protect mammalian cells against oxidative damage by changing the expression of miRs. Therefore, it is proposed that a similar mechanism of protection by antioxidants against stress may be found in hearing disorders. This review article discusses novel concepts: (a) alterations in the expression of miRs may be involved in the pathogenesis of hearing disorders; (b) presents evidence from neurons and glia cells to show that oxidative stress and pro-inflammatory cytokines mediate their damaging effects by altering the expression of miRs; and proposes that a similar mechanism of damage by these biochemical events may be found in hearing loss; and (c) present data to show that antioxidants protect mammalian cells against oxidative by altering the expression of miRs. A similar role of antioxidants in protecting against hearing disorders is put forward. New studies are proposed to fill the gaps in the areas listed above.

Keywords: MicroRNAs, hearing disorders, oxidative stress, inflammation, antioxidants

\section{INTRODUCTION}

MicroRNAs (miRs) are evolutionarily conserved small non-coding single-stranded RNAs of approximately 22 nucleotides in length, and are present in all living organisms including humans (Lee et al., 1993; Wightman et al., 1993; Macfarlane and Murphy, 2010; Londin et al., 2015). The biogenesis of miRs is very complex and involves multiple biochemical steps. The majority of miRs 
are transcribed by RNA polymerase II (Pol II), while some are transcribed by RNA polymerase III (Pol III) from the non-coding region of the DNA to produce primary miRs (pri-miRs). Pri-miRs undergo a nuclear cleavage by ribonuclease III Drosa to generate precursor-miRs (pre-miRs) that migrate to the cytoplasm where they are further cleaved by ribonuclease III Dicer to ultimately form mature singlestranded miRs with the help of another protein argonaute (Ago; Hutvágner et al., 2001; Lee et al., 2003; Denli et al., 2004; Macfarlane and Murphy, 2010). Each miR binds to its complimentary sequences in the $3^{\prime}$-untranslated region ( $3^{\prime}$-UTR) of the mRNA, promotes degradation of the mRNA transcript, and prevents translation of the message of protein. In this manner, miRs regulate the translation of pro-apoptotic or anti-apoptotic proteins from their respective mRNAs, depending upon whether they receive damaging or protective signal.

miRs are expressed in the normal inner ear cells, and play an essential role in their development, differentiation and survival (Friedman et al., 2009; Ushakov et al., 2013). In mouse embryonic inner ears, considerable expression of miR-376a-3p, miR-376-b$3 p$, and miR-376-c-3p that regulate the levels of phosphoribosyl pyrophosphate synthetase 1 (PRPS 1) were found (Yan et al., 2012). The PRPS 1 protein is important for preserving hair cell function. Mutations in the gene coding for this protein are associated with a spectrum of non-syndromic and syndromic forms of hearing loss. Using inner hair cell line (HE1-OC1 cells), miR-96 and miR183 was found to regulate the levels of chloride intracellular channel 5 (CLIC5) protein. Overexpression of these miRs reduced the levels of CLIC5 (Gu et al., 2013). Expression of $157 \mathrm{miRs}$ in the inner ear sensory epithelial cells, and 53 miRs were differently expressed in cochlear and vestibular cells (Elkan-Miller et al., 2011). Among these, miR135b regulates the levels of PSIP1-p75 that had multiple cellular functions including DNA repair (Pradeepa et al., 2014) and attenuates oxidative stress (Basu et al., 2012). Using embryonic inner ear cell line (UB/OC-1), it was shown that overexpression of miR-210 support differentiation from epithelial cells to sensory hair cells (Riccardi et al., 2016). There were $455 \mathrm{miRs}$ common to both cochlear and vestibular sensory epithelial cells, with 30 miRs unique to the cochlea, and $44 \mathrm{miRs}$ unique to the vestibule. Among these, miR675-5p with its target protein Arhgap12, a GTPase activating protein has been identified (Rudnicki et al., 2014). MiR-194 is expressed in spiral ganglia neurons of mouse inner ear where it may play a role in differentiation of neurons (Wang X. R. et al., 2010). The family of miR-183 consisting of mir-96, miR-182, and miR-183 was strongly expressed in the inner ear hair cells where they play a role in differentiation of primary sensory cells (Li et al., 2010; Zhang et al., 2015). MiR-124 regulated the fate of cells in the developing organ of Corti that contains sensory hair cells and supporting cells (Huyghe et al., 2015).

Since miRs are prominently expressed in the inner ear, it is likely that alterations in their expression may be involved in hearing disorders induced by diverse groups of ototoxic agents, such as chronic and intense noise, vibrations, gentamicin, ionizing radiation, cisplatin, large doses of aspirin, bacterial and viral infection, gene mutations and advanced age. Indeed, changes in the expression of miRs occur in hearing disorders but not understood what signals cause these changes in the expression of miRs that play a role in the pathogenesis of hearing loss. In neurodegenerative disease such as Alzheimer's disease $(\mathrm{AD})$, increased oxidative stress and products of chronic inflammation such as pro-inflammatory cytokines act as one of the signals that mediate the damaging effects of these biochemical events on the non-auditory neurons (Prasad, 2017). Since increased oxidative stress (Clerici et al., 1995; Van Campen et al., 2002; Henderson et al., 2006; Neri et al., 2006; Vlajkovic et al., 2013; Turcot et al., 2015) and inflammation (Aminpour et al., 2005; Masuda et al., 2006, 2012; Kim et al., 2008; Sziklai et al., 2009; Yamamoto et al., 2009; Verschuur et al., 2014) play a central role in the pathogenesis of hearing defects induced by the ototoxic agents, it is likely that reactive oxygen species (ROS) and pro-inflammatory cytokines may mediate their damaging effects on the hair cells by altering the expression of miRs. This possibility is supported by the fact that the damaging effects of ROS and pro-inflammatory cytokines on the non-auditory neurons are mediated by altering the expression of miRs (Prasad, 2017).

In the non-auditory cells, antioxidants in addition to donating an electron to the molecules with an unpaired electron, they may also mediate their protective effects against oxidative damage by altering the expression of miRs (Prasad, 2017). Since antioxidants reduced the risk of developing hearing defects presumably by decreasing oxidative stress (Sato, 1988; Hou et al., 2003; Kalkanis et al., 2004; Angeli et al., 2005; Husain et al., 2005; McFadden et al., 2005; Kopke et al., 2007; Savastano et al., 2007; Haase et al., 2011; Kapoor et al., 2011; Kang et al., 2013; Seidman et al., 2013; Ojano-Dirain et al., 2014; Kaya et al., 2015), it is likely that protective mechanisms of antioxidants in the auditory cells may be mediated via altering the expression of miRs.

This review article describes studies on alterations in the expression of miRs in the pathogenesis of hearing disorders. It offers evidence from the studies on the non-auditory cells (neurons and glia cells) to support the idea that oxidative stress and pro-inflammatory cytokines may mediate their damaging effects by altering the expression of miRs and proposes studies to demonstrate a similar role of these biochemical events in the auditory cells. This review article also discusses data from the non-auditory cells to show that the protective effects of antioxidants against oxidative damage are mediated in part by altering the expression of miRs. Parallel investigations are needed to look for a similar role of antioxidants in protecting against hearing disorders.

\section{ALTERATIONS IN miRs EXPRESSION IN HEARING DISORDERS}

1. Age-related hearing loss is caused by the cochlear degeneration. Overexpression of miR-29b induced degeneration of cochlear hair cells by decreasing the levels of its target proteins. These key proteins are: (a) silent mating type information regulation 2 homolog 1 (SIRT1), a $\mathrm{NAD}+$ dependent protein deacetylase, which down regulates 
inflammatory processes; and (b) proliferator-activated receptor-gamma coactivator $1 \alpha$ (PGC-1 $\alpha)$. PGC- $1 \alpha$ is a stimulator of mitochondrial biogenesis and a regulator of energy metabolism, whose inhibition can lead to impaired mitochondrial function and cochlear hair cell apoptosis in mice (Xue et al., 2016). This study was confirmed by the opposite experiment where inhibition of miR-29b increased the levels of SIRT1 and PGC-1 $\alpha$, and deceased apoptosis of cochlear hair cells (HEI-OC1 inner ear cell line).

2. The expression of Dicer, a ribonuclease III that cleaves pre-miR to form mature $\mathrm{miR}$ in the cytoplasm was downregulated in the whole blood of patients with idiopathic sudden sensorineural hearing loss (SSNHL; Kim et al., 2015). Thus, the expression of miRs may also be reduced in this form of hearing loss. However, the expression of Drosha was not altered in the whole blood of these patients suggesting that the processing of miRs at the nuclear level was not affected. This suggests that in SSNHL, alterations in controlling the expression of miRs occur at the level of cytoplasm and not at the nucleus.

3. The expression of miR-34a which causes apoptosis, increased in the cochlea of mice as function of aging, whereas the levels of SIRT1 decreased in these animals. Overexpression of miR-34a also inhibited SIRT1in the inner hair cell line (HE1-OCI). Resveratrol, an activator of SIRT1, decreased miR-34a overexpression, protected hair cells, and reduced hearing loss in mice (Xiong et al., 2015).

4. Degeneration of the organ of Corti, the auditory hair cells that transduces mechanical stimuli to electrical signal in the inner ear, is the major cause of age-related hearing loss. The expression of miR-29 family and miR-34 family that regulate pro-apoptotic pathways was upregulated with aging. However, members of miR-181 and miR-183 responsible for proliferation and differentiation were downregulated during age-related hearing loss (Zhang et al., 2013).

5. MiR-431, which targets the protein Eya4 is highly expressed in the spinal ganglion neurons (SGNs) of the cochlea of newborn mice, and decreases during further development. Inhibition of the cochlear Eya4 protein in miR-431 overexpressing mice led to apoptosis of SGNs and caused hearing loss (Fan et al., 2016).

\section{MUTATION IN miR INDUCES NSHL}

Point mutation in miR-96 has been associated with the progressive hearing loss in hereditary nonsyndromic hearing loss (NSHL) both in humans and mice (Friedman and Avraham, 2009; Kuhn et al., 2011). Treatment of mice with N-ethyl-Nnitrosurea (ENU) resulted in mutation in miR-96 that caused hearing loss associated with the damage to the hair cell function and differentiation (Lewis et al., 2009). The mouse model carrying mutated miR-96 is referred to as diminuendo and is considered a good model to study mechanisms of hearing loss. Mutation in miR-96 was also found in two Spanish families with autosomal dominant NSH (Soldà et al., 2012).

\section{CHANGES IN THE EXPRESSION OF miRs IN NOISE-INDUCED HEARING LOSS}

1. Exposure to intense noise that caused damage to the cochlear hair cells, led to simultaneous decrease of miR-183 levels and corresponding enhancement of its target protein Taok1 (Tao kinase1, a serine/threonine-proten kinase1). This observation was confirmed in the cochlear organotypic culture where inhibition of miR-183 expression resulted in enhanced levels of Taok1 together with apoptosis of hair cells (Patel et al., 2013). Exposure to noise downregulated the expression of miR-176 leading to increased Taok1 levels and apoptosis of the cochlear sensory epithelial cells (Patel et al., 2013).

2. The expression of three miRs: miR-183, miR-96 and miR-182 was decreased 28 days after exposure to noise. This was associated with reduced number of outer hair cells many of which were damaged (Zhang Z. et al., 2014).

3. In male textile workers with noise-induced hearing loss, the plasma levels of miR-16-5p, miR-24-3p, miR-185-5p and miR-451a were upregulated in comparison to those who were exposed to noise exposure but had not developed hearing loss, whereas the plasma levels of miR-24-3p and miR-185-5p and miR-451a were downregulated in individuals exposed to noise in relative to those not exposed (Ding et al., 2016). The protein targets for these miRs were not identified. Plasma levels of these miRs could be of diagnostic value of noise exposureinduced hearing disorders as well as to noise exposure. Further studies are needed to confirm these results.

\section{CHANGES IN THE EXPRESSION OF miRs IN KANAMYCIN-INDUCED HEARING DISORDERS}

Treatment of mice with kanamycin increased the expression of miR-34a and miR-34c, and induced apoptosis in the cochlear hair cells, including stria vascularis cells, supporting cells and SGNs (Yu et al., 2010). These effects of kanamycin were associated with increased levels of calpain.

\section{ALTERATIONS IN THE EXPRESSION OF miRs IN DAMAGED AUDITORY NERVOUS SYSTEM}

Progressive degeneration of SGNs caused sensorineural hearing loss (SNHL). Overexpression of miR-204 suppressed the viability of SGNs by reducing the levels of its target transmembrane protease, serine-3 (TMPRSS3; Li et al., 2014). Therefore, reducing the expression of miR-204 may prevent the development of SNHL. Mutation in the TMPRSS3 gene also caused non-syndromic autosomal recessive deafness with bilateral hearing loss in utero or in immature mice. This disease is characterized by degeneration of the organ of Corti and cochlear hair cell loss. Reducing the expression of miR-204 may also help to decrease the development of SNHL and may constitute a therapeutic approach to non-syndromic autosomal recessive deafness. 
TABLE 1 | Upregulated and downregulated microRNAs (miRs) in induced-hearing loss.

\begin{tabular}{|c|c|c|}
\hline Inducing agents & Upregulated microRNAs & Target proteins \\
\hline \multirow[t]{3}{*}{ Age } & miR-29b, miR-34a & SIRT1, PGC-1 $\alpha$ \\
\hline & miR-29 and miR-34 families & \\
\hline & $\operatorname{miR}-431$ & Eya4 \\
\hline Noise & $\begin{array}{l}{ }^{* *} \operatorname{miR}-16-5 p, \text { miR-24-3p, miR-185p5 } \\
\text { miR-451a }\end{array}$ & Not identified \\
\hline \multirow[t]{2}{*}{ SNHL } & miR-204 & TMPRSS3 \\
\hline & Downregulated microRNAs & \\
\hline NSHL & mutated miR-96 & Not identified \\
\hline SSNHL & Dicer & \\
\hline \multirow[t]{2}{*}{ Noise } & miR181, miR-176 & Toak1 \\
\hline & $\begin{array}{l}\text { *miR-96, mir-182, miR-183 } \\
\text { miR-24-3p, miR-185-5p, miR-451a }\end{array}$ & Not identified \\
\hline
\end{tabular}

SIRT1, Silent mating type information regulation 2 homolog 1; PGC-1 , Proliferator-activated receptor-gamma coactivator1 $\alpha$; Eya4, Eye absent homolog protein4; TMPRSS3, Transmembrane protease, serine-3; Taok1, Tao kinase1 (serine/theorine-protein kinase1); SNHL, Sensorineural hearing loss; SSNHL, Sudden sensorineural hearing loss; NSHL, Nonsyndromic hearing loss. ${ }^{* *}$ Levels of noise exposure leading to hearing loss, * Levels of noise exposure not causing hearing loss.

It is not established, whether changes in the expression of specific miRs are due to alterations in the rate of their transcription, processing by Drosha in the nucleus and Dicer in the cytoplasm or their stability.

Additional studies are needed to explore the effects of different ototoxic agents on the expression of miRs and their respective target proteins in the hair cells and SGNs in culture as well as in animals. In addition, the blood levels of miRs in patients with established hearing loss, and those who have been exposed to a ototoxic agent, but have not developed hearing defects, would also be useful and could readily be investigated.

Table 1 summarizes the alterations in expression of miRs in hearing loss induced by diverse agents and adverse health conditions.

\section{OXIDATIVE STRESS REGULATES THE EXPRESSION OF miRs}

As mentioned earlier in this manuscript, increased oxidative stress is important in the development of hearing defects and alterations in the expression of miRs occur in this disease. Therefore, it is likely that damaging effects of oxidative stress may be mediated by such alterations in hearing disorders. This is substantiated by the studies on auditory and non-auditory cells. These studies are briefly described here.

\section{Auditory Cells}

Although increased oxidative stress is involved in the pathogenesis of hearing disorders, only a few studies are available on the effects of this biochemical event on changes in the expression of miRs in the cochlear hair cells.

1. Increased oxidative stress induced by tert-butylhydroperoxide (t-BHP) enhanced the expression of 24 miRs. Among these, six miRs miR-1934, miR-411, miR-717, miR-503, miR-467e and miR-699o that regulate apoptosis and proliferation of the cochlear hair cells were strongly expressed (Wang et al., 2016). ROS generated by the treatment with $\mathrm{t}-\mathrm{BHO}$ increased the expression of $35 \mathrm{miRs}$ and decreased the expression of 40 miRs, and inhibited the proliferation of hair cells (HE1-C1; Wang Z. et al., 2010).

2. ROS generated by exposure to ionizing radiation enhanced the expression of miR-207 in the hair cell line (HE1-OC1). This microRNA increased radiation-induced apoptosis and DNA damage by inhibiting its target protein AKt3. This was further supported by the fact that inhibiting the levels of AKt3 mimicked the effects of miR-207 (Tan et al., 2014).

3. In diabetic mice with high a high level of internal oxidative stress, the expression of miR34a was elevated and this inhibited the levels of SIRT1, increased HIF-1alpha, and promoted apoptosis in the hair cells (HE1-OC1). This finding indicated that downregulation of miR-34a may help in diabetic-related hearing loss (Lin et al., 2017).

\section{Non-Auditory Cells (Neurons and Non-Neuronal Cells)}

In the non auditory cells (neuronal and non-neuronal cells) oxidative stress mediates its damaging effects by altering the expression of miRs (Prasad, 2017).

1. Treatment of human neurons in culture with hydrogen peroxide $\left(\mathrm{H}_{2} \mathrm{O}_{2}\right)$, upregulated the levels of miR-153 which decreased Nrf2 levels by binding to its 3 '-UTR mRNA leading to increased oxidative damage. This was supported by the fact that a mutation in miR-153, anti-miR-153 compound or Nrf2 cDNA devoid of $3^{\prime}$-UTR site protected neurons from $\mathrm{H}_{2} \mathrm{O}_{2}$-induced oxidative damage by activating $\mathrm{Nrf} 2$ (Narasimhan et al., 2014 \#141). Reduction in the levels of Nrf2 would lead to reduction in the amounts of cytoprotective enzymes including antioxidant enzymes and phase-2-detoxifying enzymes leading to increased oxidative stress.

2. Treatment of rat spinal cord neurons with $\mathrm{H}_{2} \mathrm{O}_{2}$ upregulated the expression of miR-146 a, miR-21 and miR-150 and this resulted in apoptosis of neurons. Silencing of only miR-21 expression diminished $\mathrm{H}_{2} \mathrm{O}_{2}$-induced cell death by decreasing oxidative stress (Jiao et al., 2015). Conversely, increased expression of miR-21 reduced the levels of Nrf2 by binding to its $3^{\prime}$-UTR mRNA site.

3. Hyperoxia increased the expression levels of miR-185 and caused cell death in human lung epithelial cells in culture (Zhang et al., 2016). This upregulation of miR-185 inhibited histone deacetylase- 4 and led to DNA damage and apoptosis. MC1586, an inhibitor of histone deacetylases, increased the expression of miR-185, and this also caused cell death (Zhang et al., 2016).

4. Oxidative damage induces premature senescence in an aging animal model. Oxidative stress increased the expression of miR-24 and reduced the levels of DNA topoisomerase-1 (TOP1) levels. TOP1 is an enzyme regulating DNA topology, and reduction of it's concentration led to senescence of 
TABLE 2 | Reactive oxygen species (ROS) and pro-inflammatory cytokine alter the expression of miRs in neurons.

\begin{tabular}{ll}
\hline ROS-induced upregulation of microRNAs & Target proteins \\
\hline MiR-21, miR24, miR-146a, miR-150, miR-153 & $\begin{array}{l}\text { Nrf2, TOP 1 and histone } \\
\text { deacetylase }\end{array}$ \\
$\begin{array}{l}\text { Pro-inflammatory cytokine-induced upregulation } \\
\text { of microRNAs }\end{array}$ & \\
MiR-7, mirR-9, miR-34a, miR-125b, miR-146a, & Not identified \\
miR-155 &
\end{tabular}

Nif2, Nuclear transcriptional factor-2. TOP1, DNA topoisomerase 1. This table was reproduced from a previous publication (Prasad, 2017).

fibroblasts (Bu et al., 2016). TOP1 is thus likely to be the target protein for miR24.

These reports indicate that ROS may be one of the signals that regulates the expression of key miRs that, by decreasing the action of their target proteins namely Nrf2, TOP1 and histone deacetylase, leads to degeneration of neurons.

Additional studies should be performed on the effects of ROS donors on the expression of miRs in cultured hair cells and SGNs, and in animals following exposure to ROS donors. In addition, the levels of markers of oxidative damage and expression of miRs could be looked for in the blood of patients with established hearing defects as well as in individuals exposed to ototoxic agents, but have not yet developed deafness.

Table 2 summarizes the effects of ROS on the expression of miRs.

\section{PRO-INFLAMMATORY CYTOKINES UPREGULATE EXPRESSION OF miRs}

As mentioned earlier in this manuscript, inflammation is involved in the pathogenesis of hearing defects and alterations in the expression of miRs occur in this disease. Therefore, it is likely that damaging effects of inflammation may be mediated by such alterations in hearing loss. This possibility is supported by the investigations on non-auditory cells (neurons and astroglia) showing that pro-inflammatory cytokines bring about their damaging effects in part, by altering the expression of miRs (Prasad, 2017). These studies are briefly described here.

1. ROS and pro-inflammatory NF- $\kappa$ B induced by a combination of iron and aluminum sulfate) upregulated the expression of miR-125b and miR-146a in cultured human astroglial cells (Pogue et al., 2011). Phenylbutyl nitrone, an antioxidant; and curcumin, an inhibitor of NF- $\kappa \mathrm{B}$, both prevented this upregulation (Pogue et al., 2011). Treatment of human astroglial cells in culture with IL- $1 \beta$, a pro-inflammatory cytokine elevated the expression of miR-146a causing cell death. These findings show that pro-inflammatory cytokines act as one of the signals that upregulate miRs.

2. The pro-inflammatory transcriptional factor $N F-\kappa B$ upregulated the levels of miR-7, miR-9, miR-34a, miR-125b, miR-146a and miR-155 in cultured human neuronal-glial cells (Zhao et al., 2015). Treatment of human primary neurons in culture with TNF- $\alpha$ increased the expression of miR-146a and miR-155 (Lukiw et al., 2012).
These studies show that pro-inflammatory cytokines mediate their degenerative effects on neurons and glia cells at least in part by upregulating the expression of miRs. Studies similar to those proposed under the section of oxidative stress should be performed on the auditory cells exposed to pro-inflammatory cytokines.

Table 2 summarizes the effects of pro-inflammatory cytokines on the expression of miRs.

\section{ANTIOXIDANTS ALTER THE EXPRESSION OF miRs}

Antioxidants protect hair cells against oxidative damage and prevent hearing loss (Prasad, 2011). Studies on non-auditory cells revealed that the protective action of antioxidants against oxidative damage was in part mediated by altering the expression of miRs (Prasad, 2017). Thus, it is likely that antioxidants may also protect the inner ear cells against inflammatory damage by altering the expression of miRs. Investigations on the effects of antioxidants on the expression of miRs in non-auditory cells are described here.

\section{Resveratrol-Induced Increase in the Expression of microRNAs}

Treatment with resveratrol upregulated the expression of miR-328, and in consequence inhibited the production of its target protein metalloproteinase-2 (MMP-2) in osteosarcoma cells (Yang et al., 2015). Such treatment also enhanced the expression levels of miR-137, with a corresponding inhibition of its target protein, histone methyltransferease enhancer of Zest 2 polycomb repressive complex 2 subunit (EZH2) in neuroblastoma cells (Ren et al., 2015). Resveratrol treatment of cultured human colon cancer cells increased the expression of miR-663, which decreased the levels of its target proteins, program cell death protein4 (PDCD4), phosphatase and tensin homolog (PTEN) and transforming growth factor (TGF; Tili et al., 2010). In a transformed human bronchial epithelial cell line, resveratrol treatment also upregulated miR-622 resulting in inhibition of its target protein K-ras (Han et al., 2012). In the peripheral blood mononuclear cells of hypertensive male patients with type 2 diabetes, daily oral supplementation with grape seed extract rich in resveratrol for a year increased the expression of miR-21, miR-181b, miR-663, miR-30c2, miR-155 and miR-34a and thereby reduced the levels of their target pro-inflammatory cytokines $\mathrm{C}-\mathrm{C}$ motif chemokine ligand 3 (CCl3), IL-1 $\beta$ and TNF- $\alpha$ (Tomé-Carneiro et al., 2013).

\section{Resveratrol-Induced Decrease in the Expression of microRNAs}

Resveratrol treatment reduced the expression levels of miR-134 and miR-124. Since cyclic-AMP response binding protein (CREB), a nuclear transcriptional factor, is one of their target proteins, their decreased expression led to production of increased levels CREB leading to enhanced synthesis of BDNF (Zhao et al., 2013). Resveratrol treatment decreased the expression of miR-21 in several cancers cells in culture 
(Sheth et al., 2012; Li et al., 2013; Liu et al., 2013; Zhou et al., 2014), and miR-33a and miR-122 in isolated hepatic cells (Baselga-Escudero et al., 2014). Treatment with grape seed extract deceased the expression of miR-27a which increased the levels of its target protein Forkhead box protein O1 (FOXO1; Ma et al., 2015). This protein can reduce stress response.

\section{Isoflavone-Induced Increase in the Expression of microRNAs}

Isoflavone treatment increased the expression of miR-200b, miR-200c, miR-let-7b, miR-let-7c, miR-let-7d, and miR-let-7e resulting in reduced levels of their target proteins zinc finger E-box-binding homeobox 1 (ZEB1) and vimentin in pancreatic cancer cells ( $\mathrm{Li}$ et al., 2009). In cultured breast cancer cells, treatment with the natural compounds, such as enoxolone (or glycyrrhetinic acid), a component of licorice with antiviral, anti-bacterial and antifungal activities, and magnolol, a component of the bark of Magnolia officinalis, upregulated the expression levels of miR-200c which inhibited its target protein ZEB1 (Hagiwara et al., 2015). These changes in the expression of miRs were associated with reduced growth of cancer cells.

\section{Genistein-Induced Decrease in the Expression of microRNAs}

Treatment of cultured pancreatic cancer cells with genistein downregulated the expression of miR-223 and miR-34a which increased the levels of their target proteins F-box and WD repeat domain-containing 7 (Fbw7) and Notch-1 and reduced growth (Xia et al., 2012; Ma et al., 2013).

\section{Quercetin-Induced Increase in the Expression of microRNAs}

The growth of breast cancer cells in culture was inhibited after treatment with quercetin. This agent also enhanced the expression of miR-146a (Tao et al., 2015). Quercetin upregulated the expression of hepatic miR-122 and miR-125b and this was associated with decreased levels of inflammatory genes (BoeschSaadatmandi et al., 2012).

\section{Curcumin-Induced Decrease in the Expression of microRNAs}

In a human primary culture of neuronal-glia cells, curcumin treatment prevented ROS and NF- $\kappa \mathrm{B}$-induced upregulation of miR-125b and miR-146a (Pogue et al., 2011). The pro-inflammatory cytokine IL- $1 \beta$ increased the expression of miR-146a; however, curcumin treatment prevented IL-1 $\beta$ induced upregulation of miR-146a in human primary culture of neuronal-glial cells (Li et al., 2011). This implies a reciprocal regulatory relationship between miRs and their target proteins. Increased expression of miR-146a was associated with enhanced senile plaque density and synaptic pathology in transgenic mouse models of AD (Tg2576 and 5XFAD). Curcumin suppressed the expression of miR-21 and elevated its target protein PTEN in human non-small cell lung carcinoma (Zhang W. et al., 2014).

\section{Curcumin-Induced Increase in the Expression of microRNAs}

Curcumin increased the expression of miR-22 (Sun et al., 2008) in human pancreatic cancer cells. Curcumin-induced upregulation of miR-22, and thereby reduced the level of its target protein transcriptional factor-1 (SP-1) by binding to its $3^{\prime}$-UTR mRNA. Silencing the expression of miR-22 enhanced the levels of SP-1. Treatment of cultured bladder cancer cells with curcumin upregulated the expression of miR-203, which reduced the levels of its target proteins protein kinase B (Akt2) and src tyrosine protein kinase (Saini et al., 2011). In breast cancer cells, treatment with curcumin upregulated the expression of miR-7, which decreased the concentration of its target protein SET8 histone lysine methyltransferase. Curcumin increased the expression of $\mathrm{miR}-181 \mathrm{~b}$ and reduced the levels of its target protein chemokine (C-X-C Motif) ligand-1 (CXCL-1; Kronski et al., 2014). Alterations in the expression of miRs were associated with growth inhibition.

\section{Coenzyme Q10- and $\mathrm{N}$-Acetylcysteine-Induced Decrease in the Expression of microRNAs}

In primary culture of umbilical vein endothelial cells, treatment with coenzyme Q10 reduced lipopolysaccharide (LPS)-induced elevation of the expression of miR-146a and corresponding reduction of its target protein IL-1receptor associated kinase-1 (ILRAL-1; Olivieri et al., 2013).

Increased oxidative stress induced by exposure to diesel fuel upregulated the expression of miR-21, miR-30e, miR-215 and miR-144 in the blood of patients with mild asthma. The upregulation of miR-144 resulted in reduction of its target protein Nrf2 and this then caused decreased levels of glutamate cysteine ligase catalytic subunit (GCLC) and NAD(P) H: quinone oxidoreduxtase-1 (NQO1). Treatment with $\mathrm{N}$-acetylcysteine (NAC) attenuated this diesel fuel-induced elevation of oxidative stress and the expression of miR-144 and miR-21 (Yamamoto et al., 2013).

The studies discussed above suggest that different antioxidants affect the expression and type of miRs in a variety ways. Some antioxidants (resveratrol and curcumin) can both increase and decrease the expression of miRs, others (isoflavone and quercetin) are only reported to enhance them, while others (genistein and NAC) may only decrease them. It is interesting to note that resveratrol treatment upregulates and downregulates the expression levels of miR-21, whereas curcumin and NAC only downregulate the expression of miR-21. Upregulation of miR-21 appears to reduce the levels of pro-inflammatory cytokines, whereas its downregulation reduces the intensity of oxidative stress by enhancing Nrf2 level. The same microRNA appears to target the mRNAs for several proteins thus facilitating a decrease in both oxidative stress and inflammation.

The upregulation and downregulation of miR-21 by resveratrol involve different target proteins but the overall effect is the reduction of oxidative stress and inflammatory 
TABLE 3 | Effects of antioxidants compounds on the expression of miRs.

\begin{tabular}{lll}
\hline Antioxidants & Upregulation & Downregulation \\
\hline Resveratrol & miR-21, miR-30c2, miR-34a, miR-137, miR-155, miR-181b, miR-328, miR-622, miR-663 & miR-21, miR-27a, miR-33a, miR-122, miR-124, \\
& miR-134 \\
Curcumin & miR-7, miR-22, miR-181b, miR-203 & miR-21, miR-125b miR-146a \\
Isoflavone & None-7b, miR-let-7c, miR-let-7d miR-let-7e, miR-200b, miR-200c & None \\
Genistein & miR-122, miR-125b, miR-146a & miR-34a, miR-223 \\
Quercetin & None & None \\
Coenzyme Q10 & None & miR-146a \\
N-acetylcysteine & miR-21, miR-144
\end{tabular}

It is interesting to note that resveratrol treatment upregulated and downregulated the expression levels of miR-21, whereas curcumin and $\mathrm{N}$-acetylcysteine downregulated the expression levels of miR-21. Upregulated and downregulated miR-21 used different target proteins to reduce oxidative stress and inflammation. Similarly, miR-146a was upregulated by the quercetin treatment, whereas it was downregulated by the treatment with curcumin and coenzyme Q10. This table was reproduced from a previous publication (Prasad, 2017).

processes. Similarly, miR146a was upregulated by the quercetin treatment, while it was down regulated by the treatment with curcumin and coenzyme Q10. However differing target proteins lead to the amelioration of oxidant and inflammatory event in either case.

New investigations on the effect of antioxidants on changes in the expression of miRs in cultured hair cells and SGNs and in animals following treatment with ototoxic agents should be performed.

Table 3 summarizes data on the effects of antioxidants on changes in the expression of miRs in non-auditory cells.

\section{CONCLUSION}

Increased oxidative stress and chronic inflammation play an important role in the initiation and progression of hearing loss induced by diverse ototoxic agents or adverse health conditions. Some studies show that the expression of miRs is altered in hearing loss. Although increased oxidative damage and inflammation are involved in the pathogenesis of hearing disorders, the relation of these biochemical events to the expression of miRs on auditory cells remains unclear. However, in case of the non-auditory cells (neurons and glia cells), ROS and pro-inflammatory cytokines mediate their degenerative

\section{REFERENCES}

Aminpour, S., Tinling, S. P., and Brodie, H. A. (2005). Role of tumor necrosis factor- $\alpha$ in sensorineural hearing loss after bacterial meningitis. Otol. Neurotol. 26, 602-609. doi: 10.1097/01.mao.0000178121.28365.0d

Angeli, S. I., Liu, X. Z., Yan, D., Balkany, T., and Telischi, F. (2005). Coenzyme Q-10 treatment of patients with a $7445 \mathrm{~A} \rightarrow \mathrm{G}$ mitochondrial DNA mutation stops the progression of hearing loss. Acta Otolaryngol. 125, 510-512. doi: 10.1080/00016480510026232

Baselga-Escudero, L., Blade, C., Ribas-Latre, A., Casanova, E., Suárez, M., Torres, J. L., et al. (2014). Resveratrol and EGCG bind directly and distinctively to miR-33a and miR-122 and modulate divergently their levels in hepatic cells. Nucleic Acids Res. 42, 882-892. doi: 10.1093/nar/gkt1011

Basu, A., Drame, A., Muñoz, R., Gijsbers, R., Debyser, Z., Leon De, M., et al. (2012). Pathway specific gene expression profiling reveals oxidative stress genes potentially regulated by transcription co-activator LEDGF/p75 in prostate cancer cells. Prostate 72, 597-611. doi: 10.1002/pros.21463

Boesch-Saadatmandi, C., Wagner, A. E., Wolffram, S., and Rimbach, G. (2012). Effect of quercetin on inflammatory gene expression in mice liver in vivo-role effects to some extent by changing the expression of miRs in a way that allows increased production of pro-apoptotic proteins. Therefore, it is likely that a parallel mechanism of degeneration of the auditory system by these processes may be found in hearing disorders. While antioxidants protect against oxidative damage in hearing disorders, it is unknown whether they provide such protection by altering the expression of miRs. The fact that antioxidants protect the non-auditory cells against oxidative damage by altering the expression of miRs suggests that a similar mechanism of protection by antioxidants may exist in hearing disorders. New studies are suggested to fill the gaps that exist on the understanding the role of miRs in the pathogenesis of hearing disorders.

\section{AUTHOR CONTRIBUTIONS}

SCB has contributed to the writing and discussion of the contents of the manuscript. KNP is responsible for the concept, research, and writing the manuscript.

\section{FUNDING}

The accepted manuscripts in the Research Topic will be sponsored by the Hearing Center of Excellence (HCE).

of redox factor 1, miRNA-122 and miRNA-125b. Pharmacol. Res. 65, 523-530. doi: 10.1016/j.phrs.2012.02.007

Bu, H., Baraldo, G., Lepperdinger, G., and Jansen-Durr, P. (2016). mir-24 activity propagates stress-induced senescence by down regulating DNA topoisomerase 1. Exp. Gerontol. 75, 48-52. doi: 10.1016/j.exger. 2015.12.012

Clerici, W. J., DiMartino, D. L., and Prasad, M. R. (1995). Direct effects of reactive oxygen species on cochlear outer hair cell shape in vitro. Hear. Res. 84, 30-40. doi: 10.1016/0378-5955(95)00010-2

Denli, A. M., Tops, B. B., Plasterk, R. H., Ketting, R. F., and Hannon, G. J. (2004). Processing of primary microRNAs by the Microprocessor complex. Nature 432, 231-235. doi: 10.1038/nature 03049

Ding, L., Liu, J., Shen, H. X., Pan, L. P., Liu, Q. D., Zhang, H. D., et al. (2016). Analysis of plasma microRNA expression profiles in male textile workers with noise-induced hearing loss. Hear. Res. 333, 275-282. doi: 10.1016/j.heares.2015. 08.003

Elkan-Miller, T., Ulitsky, I., Hertzano, R., Rudnicki, A., Dror, A. A., Lenz, D. R., et al. (2011). Integration of transcriptomics, proteomics, and microRNA 
analyses reveals novel microRNA regulation of targets in the mammalian inner ear. PLoS One 6:e18195. doi: 10.1371/journal.pone.0018195

Fan, Y., Zhang, Y., Wu, R., Chen, X., Zhang, Y., Chen, X., et al. (2016). miR-431 is involved in regulating cochlear function by targeting Eya4. Biochim. Biophys. Acta 1862, 2119-2126. doi: 10.1016/j.bbadis.2016.08.015

Friedman, L. M., and Avraham, K. B. (2009). MicroRNAs and epigenetic regulation in the mammalian inner ear: implications for deafness. Mamm. Genome 20, 581-603. doi: 10.1007/s00335-009-9230-5

Friedman, L. M., Dror, A. A., Mor, E., Tenne, T., Toren, G., Satoh, T., et al. (2009). MicroRNAs are essential for development and function of inner ear hair cells in vertebrates. Proc. Natl. Acad. Sci. U S A 106, 7915-7920. doi: 10.1073/pnas. 0812446106

Gu, C., Li, X., Tan, Q., Wang, Z., Chen, L., and Liu, Y. (2013). MiR-183 family regulates chloride intracellular channel 5 expression in inner ear hair cells. Toxicol. in vitro 27, 486-491. doi: 10.1016/j.tiv.2012.07.008

Haase, G. M., Prasad, K. N., Cole, W. C., Baggett-Strelau, J. M., and Wyatt, S. E. (2011). Antioxidant micronutrient impact on hearing disorders: concept, rationale, and evidence. Am. J. Otolaryngol. 32, 55-61. doi: 10.1016/j.amjoto. 2009.09.002

Hagiwara, K., Gailhouste, L., Yasukawa, K., Kosaka, N., and Ochiya, T. (2015). A robust screening method for dietary agents that activate tumour-suppressor microRNAs. Sci. Rep. 5:14697. doi: 10.1038/srep14697

Han, Z., Yang, Q., Liu, B., Wu, J., Li, Y., Yang, C., et al. (2012). MicroRNA622 functions as a tumor suppressor by targeting K-Ras and enhancing the anticarcinogenic effect of resveratrol. Carcinogenesis 33, 131-139. doi: 10.1093/carcin/bgr226

Henderson, D., Bielefeld, E. C., Harris, K. C., and Hu, B. H. (2006). The role of oxidative stress in noise-induced hearing loss. Ear Hear. 27, 1-19. doi: 10.1097/01.aud.0000191942.36672.f3

Hou, F., Wang, S., Zhai, S., Hu, Y., Yang, W., and He, L. (2003). Effects of $\alpha$-tocopherol on noise-induced hearing loss in guinea pigs. Hear. Res. 179, 1-8. doi: 10.1016/s0378-5955(03)00065-0

Husain, K., Whitworth, C., Somani, S. M., and Rybak, L. P. (2005). Partial protection by lipoic acid against carboplantin-induced ototoxicity in rats. Biomed. Environ. Sci. 18, 198-206.

Hutvágner, G., McLachlan, J., Pasquinelli, A. E., Bálint, E., Tuschl, T., and Zamore, P. D. (2001). A cellular function for the RNA-interference enzyme Dicer in the maturation of the let-7 small temporal RNA. Science 293, 834-838. doi: $10.1126 /$ science. 1062961

Huyghe, A., Van den Ackerveken, P., Sacheli, R., Prévot, P. P., Thelen, N., Renauld, J., et al. (2015). MicroRNA-124 regulates cell specification in the cochlea through modulation of Sfrp4/5. Cell Rep. 13, 31-42. doi: 10.1016/j. celrep.2015.08.054

Jiao, G., Pan, B., Zhou, Z., Zhou, L., Li, Z., and Zhang, Z. (2015). MicroRNA-21 regulates cell proliferation and apoptosis in $\mathrm{H}_{2} \mathrm{O}_{2}$-stimulated rat spinal cord neurons. Mol. Med. Rep. 12, 7011-7016. doi: 10.3892/mmr. 2015.4265

Kalkanis, J. G., Whitworth, C., and Rybak, L. P. (2004). Vitamin E reduces cisplatin ototoxicity. Laryngoscope 114, 538-542. doi: 10.1097/00005537-20040300000028

Kang, H. S., Park, J. J., Ahn, S. K., Hur, D. G., and Kim, H. Y. (2013). Effect of high dose intravenous vitamin $\mathrm{C}$ on idiopathic sudden sensorineural hearing loss: a prospective single-blind randomized controlled trial. Eur. Arch. Otorhinolaryngol. 270, 2631-2636. doi: 10.1007/s00405-012-2294-y

Kapoor, N., Mani, K. V., Shyam, R., Sharma, R. K., Singh, A. P., and Selvamurthy, W. (2011). Effect of vitamin E supplementation on carbogeninduced amelioration of noise induced hearing loss in man. Noise Health 13, 452-458. doi: 10.4103/1463-1741.90327

Kaya, H., Koç, A. K., Sayin, I., Günes, S., Altintas, A., Yegin, Y., et al. (2015). Vitamins A, C, and E and selenium in the treatment of idiopathic sudden sensorineural hearing loss. Eur. Arch. Otorhinolaryngol. 272, 1119-1125. doi: $10.1007 / \mathrm{s} 00405-014-2922-9$

Kim, S., Lee, J.-H., and Nam, S. I. (2015). Dicer is down-regulated and correlated with drosha in idiopathic sudden sensorineural hearing loss. J. Korean Med. Sci. 30, 1183-1188. doi: 10.3346/jkms.2015.30.8.1183

Kim, H. J., So, H. S., Lee, J. H., Park, C., Lee, J. B., Youn, M. J., et al. (2008). Role of proinflammatory cytokines in cisplatin-induced vestibular hair cell damage. Head Neck 30, 1445-1456. doi: 10.1002/hed.20892
Kopke, R. D., Jackson, R. L., Coleman, J. K., Liu, J., Bielefeld, E. C., and Balough, B. J. (2007). NAC for noise: from the bench top to the clinic. Hear. Res. 226, 114-125. doi: 10.1016/j.heares.2006.10.008

Kronski, E., Fiori, M. E., Barbieri, O., Astigiano, S., Mirisola, V., Killian, P. H., et al. (2014). miR181b is induced by the chemopreventive polyphenol curcumin and inhibits breast cancer metastasis via down-regulation of the inflammatory cytokines CXCL1 and -2. Mol. Oncol. 8, 581-595. doi: 10.1016/j.molonc.2014. 01.005

Kuhn, S., Johnson, S. L., Furness, D. N., Chen, J., Ingham, N., Hilton, J. M., et al. (2011). miR-96 regulates the progression of differentiation in mammalian cochlear inner and outer hair cells. Proc. Natl. Acad. Sci. U S A 108, 2355-2360. doi: $10.1073 /$ pnas. 1016646108

Lee, Y., Ahn, C., Han, J., Choi, H., Kim, J., Yim, J., et al. (2003). The nuclear RNase III Drosha initiates microRNA processing. Nature 425, 415-419. doi: 10.1038/nature01957

Lee, R. C., Feinbaum, R. L., and Ambros, V. (1993). The C. elegans heterochronic gene lin- 4 encodes small RNAs with antisense complementarity to lin-14. Cell 75, 843-854. doi: 10.1016/0092-8674(93)90529-y

Lewis, M. A., Quint, E., Glazier, A. M., Fuchs, H., De Angelis, M. H., Langford, C., et al. (2009). An ENU-induced mutation of miR-96 associated with progressive hearing loss in mice. Nat. Genet. 41, 614-618. doi: 10.1038/ng.369

Li, Y. Y., Cui, J. G., Hill, J. M., Bhattacharjee, S., Zhao, Y., and Lukiw, W. J. (2011). Increased expression of miRNA-146a in Alzheimer's disease transgenic mouse models. Neurosci. Lett. 487, 94-98. doi: 10.1016/j.neulet.2010.09.079

Li, H., Jia, Z., Li, A., Jenkins, G., Yang, X., Hu, J., et al. (2013). Resveratrol repressed viability of U251 cells by miR-21 inhibiting of NF-KB pathway. Mol. Cell. Biochem. 382, 137-143. doi: 10.1007/s11010-013-1728-1

Li, H., Kloosterman, W., and Fekete, D. M. (2010). MicroRNA-183 family members regulate sensorineural fates in the inner ear. J. Neurosci. 30, 3254-3263. doi: 10.1523/jneurosci.4948-09.2010

Li, Y., Peng, A., Ge, S., Wang, Q., and Liu, J. (2014). miR-204 suppresses cochlear spiral ganglion neuron survival in vitro by targeting TMPRSS3. Hear. Res. 314, 60-64. doi: 10.1016/j.heares.2014.05.002

Li, Y., VandenBoom, T. G. II, Kong, D., Wang, Z., Ali, S., Philip, P. A., et al. (2009). Up-regulation of miR-200 and let-7 by natural agents leads to the reversal of epithelial-to-mesenchymal transition in gemcitabine-resistant pancreatic cancer cells. Cancer Res. 69, 6704-6712. doi: 10.1158/0008-5472. can-09-1298

Lin, Y., Shen, J., Li, D., Ming, J., Liu, X., Zhang, N., et al. (2017). MiR-34a contributes to diabetes-related cochlear hair cell apoptosis via SIRT1/HIF-1 $\alpha$ signaling. Gen. Comp. Endocrinol. 246, 63-70. doi: 10.1016/j.ygcen.2017.02.017

Liu, P., Liang, H., Xia, Q., Li, P., Kong, H., Lei, P., et al. (2013). Resveratrol induces apoptosis of pancreatic cancers cells by inhibiting miR-21 regulation of BCL-2 expression. Clin. Transl. Oncol. 15, 741-746. doi: 10.1007/s12094-012-0999-4

Londin, E., Loher, P., Telonis, A. G., Quann, K., Clark, P., Jing, Y., et al. (2015). Analysis of 13 cell types reveals evidence for the expression of numerous novel primate- and tissue-specific microRNAs. Proc. Natl. Acad. Sci. U S A 112, E1106- E1115. doi: 10.1073/pnas.1420955112

Lukiw, W. J., Alexandrov, P. N., Zhao, Y., Hill, J. M., and Bhattacharjee, S. (2012). Spreading of Alzheimer's disease inflammatory signaling through soluble micro-RNA. Neuroreport 23, 621-626. doi: 10.1097/wnr.0b013e32835542b0

Ma, J., Cheng, L., Liu, H., Zhang, J., Shi, Y., Zeng, F., et al. (2013). Genistein down-regulates miR-223 expression in pancreatic cancer cells. Curr. Drug Targets 14, 1150-1156. doi: 10.2174/13894501113149990187

Ma, J., Fang, B., Zeng, F., Pang, H., Ma, C., and Xia, J. (2015). Grape seed proanthocyanidins extract inhibits pancreatic cancer cell growth through down-regulation of miR-27a expression. Zhong Nan Da Xue Xue Bao Yi Xue Ban 40, 46-52. doi: 10.11817/j.issn.1672-7347.2015.01.008

Macfarlane, L. A., and Murphy, P. R. (2010). MicroRNA: biogenesis, function and role in cancer. Curr. Genomics 11, 537-561. doi: 10.2174/138920210793175895

Masuda, M., Kanzaki, S., Minami, S., Kikuchi, J., Kanzaki, J., Sato, H., et al. (2012). Correlations of inflammatory biomarkers with the onset and prognosis of idiopathic sudden sensorineural hearing loss. Otol. Neurotol. 33, 1142-1150. doi: 10.1097/MAO.0b013e3182635417

Masuda, M., Nagashima, R., Kanzaki, S., Fujioka, M., Ogita, K., and Ogawa, K. (2006). Nuclear factor-kappa B nuclear translocation in the cochlea of mice following acoustic overstimulation. Brain Res. 1068, 237-247. doi: 10.1016/j. brainres.2005.11.020 
McFadden, S. L., Woo, J. M., Michalak, N., and Ding, D. (2005). Dietary vitamin C supplementation reduces noise-induced hearing loss in guinea pigs. Hear. Res. 202, 200-208. doi: 10.1016/j.heares.2004.10.011

Narasimhan, M., Riar, A. K., Rathinam, M. L., Vedpathak, D., Henderson, G., and Mahimainathan, L. (2014). Hydrogen peroxide responsive miR153 targets Nrf2/ARE cytoprotection in paraquat induced dopaminergic neurotoxicity. Toxicol. Lett. 228, 179-191. doi: 10.1016/j.toxlet.2014.05.020

Neri, S., Signorelli, S., Pulvirenti, D., Mauceri, B., Cilio, D., Bordonaro, F., et al. (2006). Oxidative stress, nitric oxide, endothelial dysfunction and tinnitus. Free Radic. Res. 40, 615-618. doi: 10.1080/10715760600623825

Ojano-Dirain, C. P., Antonelli, P. J., and Le Prell, C. G. (2014). Mitochondriatargeted antioxidant MitoQ reduces gentamicin-induced ototoxicity. Otol. Neurotol. 35, 533-539. doi: 10.1097/MAO.0000000000000192

Olivieri, F., Lazzarini, R., Babini, L., Prattichizzo, F., Rippo, M. R., Tiano, L., et al. (2013). Anti-inflammatory effect of ubiquinol-10 on young and senescent endothelial cells via miR-146a modulation. Free Radic. Biol. Med. 63, 410-420. doi: 10.1016/j.freeradbiomed.2013.05.033

Patel, M., Cai, Q., Ding, D., Salvi, R., Hu, Z., and Hu, B. H. (2013). The miR$183 /$ Taok1 target pair is implicated in cochlear responses to acoustic trauma. PLoS One 8:e58471. doi: 10.1371/journal.pone.0058471

Pogue, A. I., Percy, M. E., Cui, J. G., Li, Y. Y., Bhattacharjee, S., Hill, J. M., et al. (2011). Up-regulation of NF-kB-sensitive miRNA-125b and miRNA-146a in metal sulfate-stressed human astroglial (HAG) primary cell cultures. J. Inorg. Biochem. 105, 1434-1437. doi: 10.1016/j.jinorgbio.2011.05.012

Pradeepa, M. M., Grimes, G. R., Taylor, G. C., Sutherland, H. G., and Bickmore, W. A. (2014). Psip1/Ledgf p75 restrains Hox gene expression by recruiting both trithorax and polycomb group proteins. Nucleic Acids Res. 42, 9021-9032. doi: 10.1093/nar/gku647

Prasad, K. N. (2017). Oxidative stress and pro-inflammatory cytokines may act as one of signals for regulating microRNAs expression in Alzheimer's disease. Mech. Ageing Dev. 162, 63-71. doi: 10.1016/j.mad.2016.12.003

Prasad, K. N. (2011). Micronutrients in Prevention and Improvement of The Standard Therapy in Hearing Disorders, Micronutrients in Health and Disease. Boraton, FL: CRC Press.

Ren, X., Bai, X., Zhang, X., Li, Z., Tang, L., Zhao, X., et al. (2015). Quantitative nuclear proteomics identifies that miR-137-mediated EZH2 reduction regulates resveratrol-induced apoptosis of neuroblastoma cells. Mol. Cell. Proteomics 14, 316-328. doi: 10.1074/mcp.M114.041905

Riccardi, S., Bergling, S., Sigoillot, F., Beibel, M., Werner, A., Leighton-Davies, J., et al. (2016). MiR-210 promotes sensory hair cell formation in the organ of corti. BMC Genomics 17:309. doi: 10.1186/s12864-016-2620-7

Rudnicki, A., Isakov, O., Ushakov, K., Shivatzki, S., Weiss, I., Friedman, L. M., et al. (2014). Next-generation sequencing of small RNAs from inner ear sensory epithelium identifies microRNAs and defines regulatory pathways. BMC Genomics 15:484. doi: 10.1186/1471-2164-15-484

Saini, S., Arora, S., Majid, S., Shahryari, V., Chen, Y., Deng, G., et al. (2011). Curcumin modulates microRNA-203-mediated regulation of the Src-Akt axis in bladder cancer. Cancer Prev. Res. 4, 1698-1709. doi: 10.1158/1940-6207. capr-11-0267

Sato, K. (1988). Pharmacokinetics of coenzyme Q10 in recovery of acute sensorineural hearing loss due to hypoxia. Acta Otolaryngol. Suppl. 458, 95-102. doi: 10.3109/00016488809125110

Savastano, M., Brescia, G., and Marioni, G. (2007). Antioxidant therapy in idiopathic tinnitus: preliminary outcomes. Arch. Med. Res. 38, 456-459. doi: 10.1016/j.arcmed.2006.12.004

Seidman, M. D., Tang, W., Bai, V. U., Ahmad, N., Jiang, H., Media, J., et al. (2013). Resveratrol decreases noise-induced cyclooxygenase-2 expression in the rat cochlea. Otolaryngol. Head Neck Surg. 148, 827-833. doi: $10.1177 / 0194599813475777$

Sheth, S., Jajoo, S., Kaur, T., Mukherjea, D., Sheehan, K., Rybak, L. P., et al. (2012). Resveratrol reduces prostate cancer growth and metastasis by inhibiting the Akt/MicroRNA-21 pathway. PLoS One 7:e51655. doi: 10.1371/journal.pone. 0051655

Soldà, G., Robusto, M., Primignani, P., Castorina, P., Benzoni, E., Cesarani, A., et al. (2012). A novel mutation within the MIR96 gene causes non-syndromic inherited hearing loss in an Italian family by altering pre-miRNA processing. Hum. Mol. Genet. 21, 577-585. doi: 10.1093/hmg/ ddr493
Sun, M., Estrov, Z., Ji, Y., Coombes, K. R., Harris, D. H., and Kurzrock, R. (2008). Curcumin (diferuloylmethane) alters the expression profiles of microRNAs in human pancreatic cancer cells. Mol. Cancer Ther. 7, 464-473. doi: 10.1158/1535-7163.MCT-07-2272

Sziklai, I., Batta, T. J., and Karosi, T. (2009). Otosclerosis: an organspecific inflammatory disease with sensorineural hearing loss. Eur. Arch. Otorhinolaryngol. 266, 1711-1718. doi: 10.1007/s00405-009-0967-y

Tan, P. X., Du, S. S., Ren, C., Yao, Q. W., Zheng, R., Li, R., et al. (2014). MicroRNA-207 enhances radiation-induced apoptosis by directly targeting Akt3 in cochlea hair cells. Cell Death Dis. 5:e1433. doi: 10.1038/cddis. 2014.407

Tao, S. F., He, H. F., and Chen, Q. (2015). Quercetin inhibits proliferation and invasion acts by up-regulating miR-146a in human breast cancer cells. Mol. Cell. Biochem. 402, 93-100. doi: 10.1007/s11010-014-2317-7

Tili, E., Michaille, J. J., Alder, H., Volinia, S., Delmas, D., Latruffe, N., et al. (2010). Resveratrol modulates the levels of microRNAs targeting genes encoding tumor-suppressors and effectors of TGF $\beta$ signaling pathway in SW480 cells. Biochem. Pharmacol. 80, 2057-2065. doi: 10.1016/j.bcp. 2010.07.003

Tomé-Carneiro, J., Larrosa, M., Yáñez-Gascón, M. J., Dávalos, A., GilZamorano, J., Gonzálvez, M., et al. (2013). One-year supplementation with a grape extract containing resveratrol modulates inflammatoryrelated microRNAs and cytokines expression in peripheral blood mononuclear cells of type 2 diabetes and hypertensive patients with coronary artery disease. Pharmacol. Res. 72, 69-82. doi: 10.1016/j.phrs. 2013.03.011

Turcot, A., Girard, S. A., Courteau, M., Baril, J., and Larocque, R. (2015). Noiseinduced hearing loss and combined noise and vibration exposure. Occup. Med. 65, 238-244. doi: 10.1093/occmed/kqu214

Ushakov, K., Rudnicki, A., and Avraham, K. B. (2013). MicroRNAs in sensorineural diseases of the ear. Front. Mol. Neurosci. 6:52. doi: 10.3389/fnmol. 2013.00052

Van Campen, L. E., Murphy, W. J., Franks, J. R., Mathias, P. I., and Toraason, M. A. (2002). Oxidative DNA damage is associated with intense noise exposure in the rat. Hear. Res. 164, 29-38. doi: 10.1016/s0378-5955(01) 00391-4

Verschuur, C., Agyemang-Prempeh, A., and Newman, T. A. (2014). Inflammation is associated with a worsening of presbycusis: evidence from the MRC national study of hearing. Int. J. Audiol. 53, 469-475. doi: 10.3109/14992027.2014. 891057

Vlajkovic, S. M., Lin, S. C., Wong, A. C., Wackrow, B., and Thorne, P. R. (2013). Noise-induced changes in expression levels of NADPH oxidases in the cochlea. Hear. Res. 304, 145-152. doi: 10.1016/j.heares.2013.07.012

Wang, Z., Liu, Y., Han, N., Chen, X., Yu, W., Zhang, W., et al. (2010). Profiles of oxidative stress-related microRNA and mRNA expression in auditory cells. Brain Res. 1346, 14-25. doi: 10.1016/j.brainres.2010. 05.059

Wang, J. Y., Xia, Y., Yang, C. C., and Wang, Z. (2016). Analysis of microRNA regulatory network in cochlear hair cells with oxidative stress injury. Zhonghua Er Bi Yan Hou Tou Jing Wai Ke Za Zhi 51,751-755. doi: 10.3760/cma.j.issn.1673-0860.2016.10.008

Wang, X. R., Zhang, X. M., Zhen, J., Zhang, P. X., Xu, G., and Jiang, H. (2010). MicroRNA expression in the embryonic mouse inner ear. Neuroreport 21, 611-617. doi: 10.1097/WNR.0b013e328338864b

Wightman, B., Ha, I., and Ruvkun, G. (1993). Posttranscriptional regulation of the heterochronic gene lin-14 by lin- 4 mediates temporal pattern formation in C. elegans. Cell 75, 855-862. doi: 10.1016/0092-8674(93) 90530-4

Xia, J., Duan, Q., Ahmad, A., Bao, B., Banerjee, S., Shi, Y., et al. (2012). Genistein inhibits cell growth and induces apoptosis through up-regulation of miR-34a in pancreatic cancer cells. Curr. Drug Targets 13, 1750-1756. doi: $10.2174 / 138945012804545597$

Xiong, H., Pang, J., Yang, H., Dai, M., Liu, Y., Ou, Y., et al. (2015). Activation of miR-34a/SIRT1/p53 signaling contributes to cochlear hair cell apoptosis: implications for age-related hearing loss. Neurobiol. Aging 36, 1692-1701. doi: 10.1016/j.neurobiolaging.2014.12.034

Xue, T., Wei, L., Zha, D. J., Qiu, J. H., Chen, F. Q., Qiao, L., et al. (2016). miR-29b overexpression induces cochlear hair cell apoptosis through the regulation of 
SIRT1/PGC-1 $\alpha$ signaling: implications for age-related hearing loss. Int. J. Mol. Med. 38, 1387-1394. doi: 10.3892/ijmm.2016.2735

Yamamoto, H., Omelchenko, I., Shi, X., and Nuttall, A. L. (2009). The influence of NF- $\mathrm{KB}$ signal-transduction pathways on the murine inner ear by acoustic overstimulation. J. Neurosci. Res. $87,1832-1840$. doi: 10.1002/jnr. 22018

Yamamoto, M., Singh, A., Sava, F., Pui, M., Tebbutt, S. J., and Carlsten, C. (2013). MicroRNA expression in response to controlled exposure to diesel exhaust: attenuation by the antioxidant $\mathrm{N}$-acetylcysteine in a randomized crossover study. Environ. Health Perspect. 121, 670-675. doi: 10.1289/ehp.1205963

Yan, D., Xing, Y., Ouyang, X., Zhu, J., Chen, Z. Y., Lang, H., et al. (2012). Analysis of miR-376 RNA cluster members in the mouse inner ear. Int. J. Exp. Pathol. 93, 450-457. doi: 10.1111/j.1365-2613.2012.00840.x

Yang, S. F., Lee, W. J., Tan, P., Tang, C. H., Hsiao, M., Hsieh, F. K., et al. (2015). Upregulation of miR-328 and inhibition of CREB-DNA-binding activity are critical for resveratrol-mediated suppression of matrix metalloproteinase-2 and subsequent metastatic ability in human osteosarcomas. Oncotarget 6, 2736-2753. doi: 10.18632/oncotarget.3088

Yu, L., Tang, H., Jiang, X. H., Tsang, L. L., Chung, Y. W., and Chan, H. C. (2010). Involvement of calpain-I and microRNA34 in kanamycin-induced apoptosis of inner ear cells. Cell Biol. Int. 34, 1219-1225. doi: 10.1042/CBI20100515

Zhang, W., Bai, W., and Zhang, W. (2014). MiR-21 suppresses the anticancer activities of curcumin by targeting PTEN gene in human non-small cell lung cancer A549 cells. Clin. Transl. Oncol. 16, 708-713. doi: 10.1007/s12094-013$1135-9$

Zhang, D., Lee, H., Cao, Y., Dela Cruz, C. S., and Jin, Y. (2016). MiR-185 mediates lung epithelial cell death after oxidative stress. Am. J. Physiol. Lung Cell. Mol. Physiol. 310, L700-L710. doi: 10.1152/ajplung.00392.2015

Zhang, Z., Liu, K., Chen, Y., Li, Z., Yan, N., and Zhang, J. (2014). The expression of miR-183 family in the pathogenesis and development of noise-induced deafness. Lin Chung Er Bi Yan Hou Tou Jing Wai Ke Za Zhi $28,468-472$.
Zhang, Q., Liu, H., McGee, J., Walsh, E. J., Soukup, G. A., and He, D. Z. (2013). Identifying microRNAs involved in degeneration of the organ of corti during age-related hearing loss. PLoS One 8:e62786. doi: 10.1371/journal.pone. 0062786

Zhang, K. D., Stoller, M. L., and Fekete, D. M. (2015). Expression and misexpression of the miR-183 family in the developing hearing organ of the chicken. PLoS One 10:e0132796. doi: 10.1371/journal.pone.0132796

Zhao, Y. N., Li, W. F., Li, F., Zhang, Z., Dai, Y. D., Xu, A. L., et al. (2013). Resveratrol improves learning and memory in normally aged mice through microRNA-CREB pathway. Biochem. Biophys. Res. Commun. 435, 597-602. doi: 10.1016/j.bbrc.2013.05.025

Zhao, Y., Pogue, A. I., and Lukiw, W. J. (2015). MicroRNA (miRNA) signaling in the human CNS in sporadic Alzheimer's disease (AD)novel and unique pathological features. Int. J. Mol. Sci. 16, 30105-30116. doi: $10.3390 /$ ijms 161226223

Zhou, C., Ding, J., and Wu, Y. (2014). Resveratrol induces apoptosis of bladder cancer cells via miR21 regulation of the Akt/Bcl2 signaling pathway. Mol. Med. Rep. 9, 1467-1473. doi: 10.3892/mmr.2014.1950

Conflict of Interest Statement: The author KNP is the Chief Scientific Officer of Engage Global that distributes nutritional products.

The other author declares that the research was conducted in the absence of any commercial or financial relationships that could be construed as a potential conflict of interest.

Copyright $\odot 2017$ Prasad and Bondy. This is an open-access article distributed under the terms of the Creative Commons Attribution License (CC BY). The use, distribution or reproduction in other forums is permitted, provided the original author(s) or licensor are credited and that the original publication in this journal is cited, in accordance with accepted academic practice. No use, distribution or reproduction is permitted which does not comply with these terms. 